\title{
On Auto-measuring of Applications Usability for Blind People
}

\author{
Mohamed Hashim Mohamed ${ }^{1}$, Abdelrahman Osman Elfaki ${ }^{2}$, Md Gapar Md Johar ${ }^{3}$ \\ ${ }_{1}^{1}$ Management and Science University-Malaysia Sudan, Khartoum, Sudanese. \\ 2 University of Tabuk, Saudi Arabia \\ *Corresponding Author: Tel: 00966531050817; email: a.elfaki@ut.edu.sa. \\ Manuscript submitted November 29, 2018; accepted January 8, 2019. \\ doi: 10.17706/jsw.14.4.146-152
}

\begin{abstract}
Usability of computer systems is the most important successful factor for blind people. AutoMeasuring of usability is a recent concept that guarantees the result is clear from human biases. This paper investigates the metrics that could be used to develop usability auto-measuring system. First, metrics are extracted from literature, and then directed questionnaire has been conducted to prove the correctness of the selected metrics. The results of questionnaires proved the correctness of the selected metrics. Finally, we have prepared for experiment to test the selected the metrics.
\end{abstract}

Key words: Application usability, blind people, measurement metrics.

\section{Introduction}

In recent years, software system usability has made some interesting advances, with more and more organizations starting to take usability seriously. Unfortunately, the average developer has not adopted these new concepts, which gives the impact that usability level of software products has not improved [1]. For blind and visually impaired people, computers are considered as one of the keys to the occupational and social interaction. Although there is no exact count of the number of visually impaired computer users, a majority of them who are employed do use computers in their work. Bosher [2] argues that computerrelated aids and equipment for blind people are not easy to learn or intuitive to use. Hence, ensuring good usability for blind people is a significant issue.

Vision-impaired people have the same eagerness to use computer applications as normal people. Difficulties of using computer application that are facing blind users have been cited in many papers, for instance [3]. On the other hand, there are many studies deals with the question of how visually impaired users can use software applications [4]. All these studies are tackling usability as the most vital factor of a successful usage of software applications. However, there are no clear software usability metrics that are designed especially to measure usability for blind people. Aljarallah and AlShathry [5] showed that the usage and acceptance rate of online applications among the blind community is not up to the expectations. The work in [5] implemented experiments for discovering acceptability problems in E-Governmental online applications for blind people.

Mostafa [6] was proved the importance of good usability for improving knowledge management skills for blind people. Al-Glaly [7] showed in her study the perplexity that disturbs blind users in choosing type of interface: audio or haptic, i.e., screen reader or Tangible screen. Sahasrabudhe \& Lockley [8] investigated blind user's accessibility and usability problems. The work in [8] found the many usability problems for blind people. Chalkia [9] proved that the needs and preferences of a user should be matched with the settings of the interfaces they use. In fact, measuring usability should be considered in designing of user 
interfaces especially for blind people. In addition, auto-measuring usability is a new concept, which is release usability measurement from user biases. As the best of our knowledge, there is no work deal with this issue before. This paper aims to find the suitable software metrics that could be used for automeasuring usability for blind users. To achieve the paper's goal, we have followed two methods. First extract metrics from related works, second to conduct experiment to auto extract metrics from user log file. In this paper, we prove the correctness of our selected metrics ( number of using delete key, number of using escape key, time spend in one page or screen, and time to complete the task) that by done questionnaire in two countries Sudan and Malaysia. Then, we have come by the experiment framework.

\section{Test the Correctness of Selected Metrics}

The definitions of the selected parameters are presented below:

a. Number of using delete key: number of times a user used the delete key to perform the whole task.

b. Number of using escape key: number of times a user used the escape key to perform the whole task.

c. Accuracy: Capability to provide correct results or effects (ISO/IEC 9126-1, 2001). In another meaning, percentage of the task correctness.

d. Number of errors: number of errors that are done by user during performing the whole task.

e. Time duration: Capability to consume appropriate task time when performing its function.

\subsection{Measuring the Ease of Use of Computer Application Interface}

\subsubsection{The "delete key" frequent usage}

Table 1. The "Delete Key" Frequent Usage

\begin{tabular}{||l|c|c|c|c||}
\hline \multirow{2}{*}{} & \multicolumn{2}{|c|}{ Malaysia } & \multicolumn{2}{c||}{ Sudan } \\
\cline { 2 - 5 } & $\mathrm{N}$ & $\%$ & $\mathrm{~N}$ & $\%$ \\
\hline Strongly agree & 4 & 8 & 7 & 14 \\
\hline Agree & 20 & 40 & 18 & 36 \\
\hline Neutral & 15 & 30 & 14 & 28 \\
\hline Disagree & 10 & 20 & 8 & 16 \\
\hline Strongly Disagree & 1 & 2 & 3 & 6 \\
\hline \hline Total & 50 & 100 & 50 & 100 \\
\hline
\end{tabular}

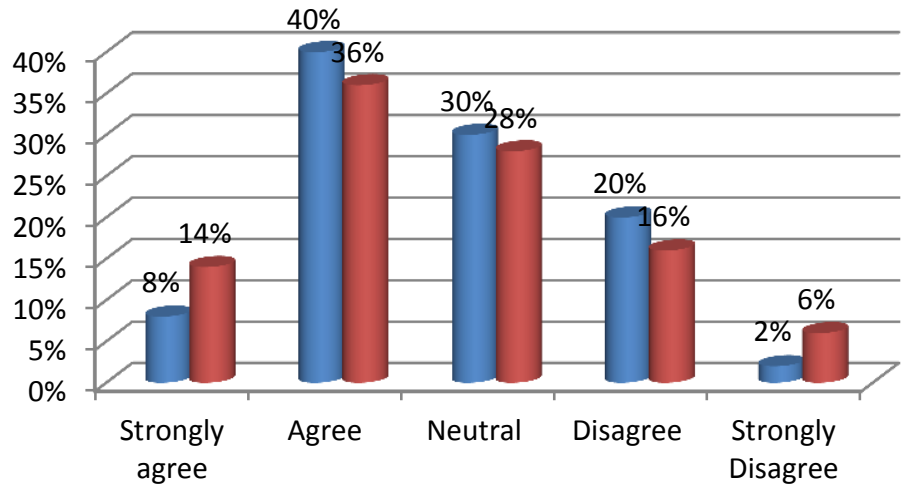

Malaysia

- Sudan

Fig. 1. The "delete key" frequent usage.

The Table 1 and Fig. 1, show responses of participants related to the question of "frequent usage of the Delete Key"; results showed that in Malaysia the highest percentage (40\%) of participants agreed also (8\%) strongly agree, $(30 \%)$ were neutral while $(20 \%)$ and $(2 \%)$ disagree and strongly dis agree respectively with the statement. Meanwhile in Sudan, the highest result was agreeing with (36\%) in contrast to the 
(16\%) whom disagreed, followed by (28\%) for neutral, (14\%) stated they strongly agree and finally (6\%) strongly disagreed.

\subsection{The "Escape Key" Frequent Usage}

Table 2. The "Escape Key" Frequent Usage

\begin{tabular}{||l|c|c||c||c||}
\hline \multirow{2}{*}{} & \multicolumn{2}{|c||}{ Malaysia } & \multicolumn{2}{c||}{ Sudan } \\
\cline { 2 - 5 } & $\mathrm{N}$ & $\%$ & $\mathrm{~N}$ & $\%$ \\
\hline \hline Strongly agree & 3 & 6 & 12 & 24 \\
\hline Agree & 16 & 32 & 10 & 20 \\
\hline Neutral & 19 & 38 & 17 & 34 \\
\hline Disagree & 8 & 16 & 5 & 10 \\
\hline Strongly Disagree & 4 & 8 & 6 & 12 \\
\hline Total & 50 & 100 & 50 & 100 \\
\hline
\end{tabular}

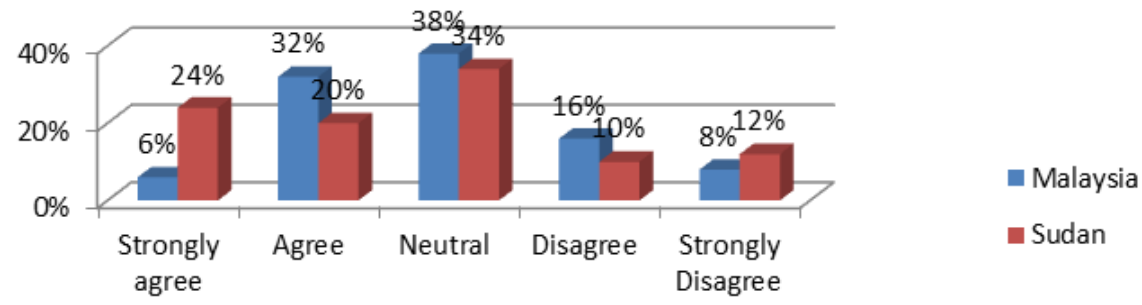

Fig. 2. The "Escape key" frequent usage.

The Table 2 and Fig. 2, above show responses of participants related to the question of "frequent usage of the Escape Key"; results showed that in Malaysia the highest percentage (38\%) of participants were neutral to the statement, (32\%) agreed and (6\%) strongly agreed that they frequently use the Escape Key while (16\%) disagree and (8\%) strongly disagreed with the statement. In Sudan the (34\%) were neutral, (20\%) agreed which is double what was recorded for disagreeing (10\%) and (12\%) strongly disagreed in which is half its opposite o strongly agreeing (24\%).

\subsubsection{Participant satisfaction of their accuracy in finishing given tasks}

Table 3. Participant Satisfaction of Their Accuracy in Finishing Given Tasks

\begin{tabular}{|l|c|c||c|c||}
\hline \multirow{2}{*}{} & \multicolumn{2}{|c||}{ Malaysia } & \multicolumn{2}{c||}{ Sudan } \\
\cline { 2 - 5 } & $\mathrm{N}$ & $\%$ & $\mathrm{~N}$ & $\%$ \\
\hline \hline Strongly agree & 8 & 16 & 5 & 10 \\
\hline Agree & 22 & 44 & 10 & 20 \\
\hline Neutral & 10 & 20 & 13 & 26 \\
\hline Disagree & 10 & 20 & 12 & 24 \\
\hline Strongly Disagree & 0 & 0 & 10 & 20 \\
\hline \hline Total & 50 & 100 & 50 & 100 \\
\hline
\end{tabular}

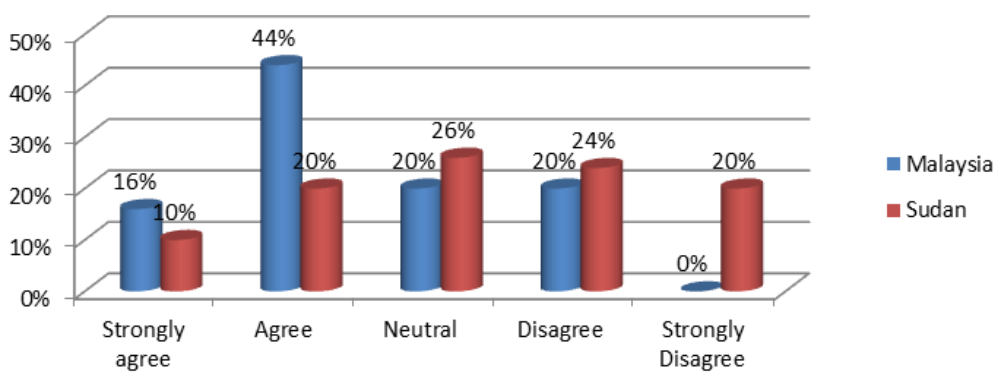

Fig. 3. Participant satisfaction of their accuracy in finishing given tasks. 
The Table 3 and Fig. 3., show responses of participants related to the statement about "their satisfaction of their accuracy in finishing a given tasks"; results of Malaysia showed that less than half (44\%) of participants agree and (16\%) strongly agree that they are satisfied with their accuracy in finishing tasks, (20\%) were neutral while (20\%) disagree with the statement. Meanwhile in Sudan the results were showed that $(20 \%)$ of participants agree and (10\%) strongly agree that they are satisfied with their accuracy in finishing tasks, the highest percentage $(26 \%)$ were neutral while $(24 \%)$ disagree and $(20 \%)$ disagree with the statement.

\subsubsection{Users' satisfaction with percentage of errors made in completing tasks}

Table 4. Users' Satisfaction with Percentage of Errors

\begin{tabular}{|l|c|c||c|c||}
\hline \multirow{2}{*}{} & \multicolumn{2}{c||}{ Malaysia } & \multicolumn{2}{c|}{ Sudan } \\
\cline { 2 - 5 } & $\mathrm{N}$ & $\%$ & $\mathrm{~N}$ & $\%$ \\
\hline \hline Strongly agree & 2 & 4 & 3 & 6 \\
\hline Agree & 20 & 40 & 11 & 22 \\
\hline Neutral & 13 & 26 & 15 & 30 \\
\hline Disagree & 9 & 18 & 10 & 20 \\
\hline Strongly Disagree & 6 & 12 & 11 & 22 \\
\hline \hline Total & 50 & 100 & 50 & 100 \\
\hline
\end{tabular}

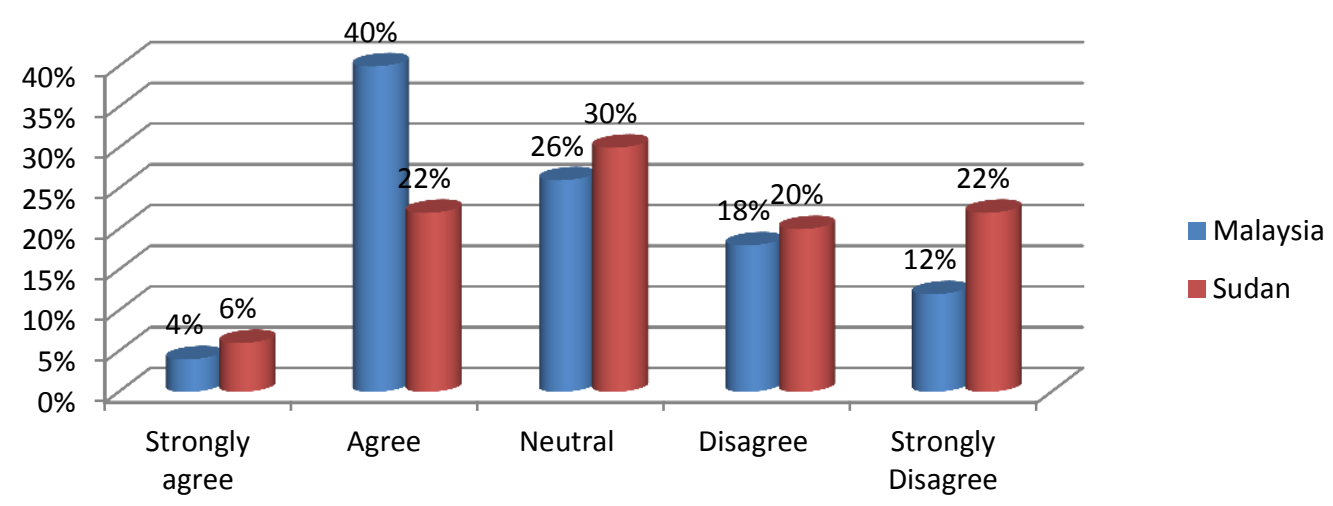

Fig. 4. Users' satisfaction with percentage of errors.

The Table 4 and Fig. 4., show responses of participants to the statement related "their satisfaction with percentage of errors made in completing tasks"; results showed that in Malaysia (40\%) agree and (4\%) strongly agree that they are satisfied with the percentage of errors they make while (26\%) were neutral while $(18 \%)$ of participants disagree and (12\%) strongly disagree with the statement.in the other side $(22 \%)$ agree and (6\%) strongly agree that they are satisfied with the percentage of errors they make while (30\%) were neutral while (18\%) of participants disagree and (22\%) strongly disagree with the statement.

\subsubsection{Users' satisfaction with the time they took to perform a specified task}

Table 5. Users' Satisfaction with the Time They Took to Perform a Specified Task

\begin{tabular}{||l|c|c||c|c|}
\hline \multirow{2}{*}{} & \multicolumn{2}{|c|}{ Malaysia } & \multicolumn{2}{c|}{ Sudan } \\
\cline { 2 - 5 } & $\mathrm{N}$ & $\%$ & $\mathrm{~N}$ & $\%$ \\
\hline \hline Strongly agree & 9 & 18 & 11 & 22 \\
\hline Agree & 19 & 38 & 18 & 36 \\
\hline Neutral & 16 & 32 & 13 & 26 \\
\hline Disagree & 5 & 10 & 6 & 12 \\
\hline Strongly Disagree & 1 & 2 & 2 & 4 \\
\hline Total & 50 & 100 & 50 & 100 \\
\hline
\end{tabular}




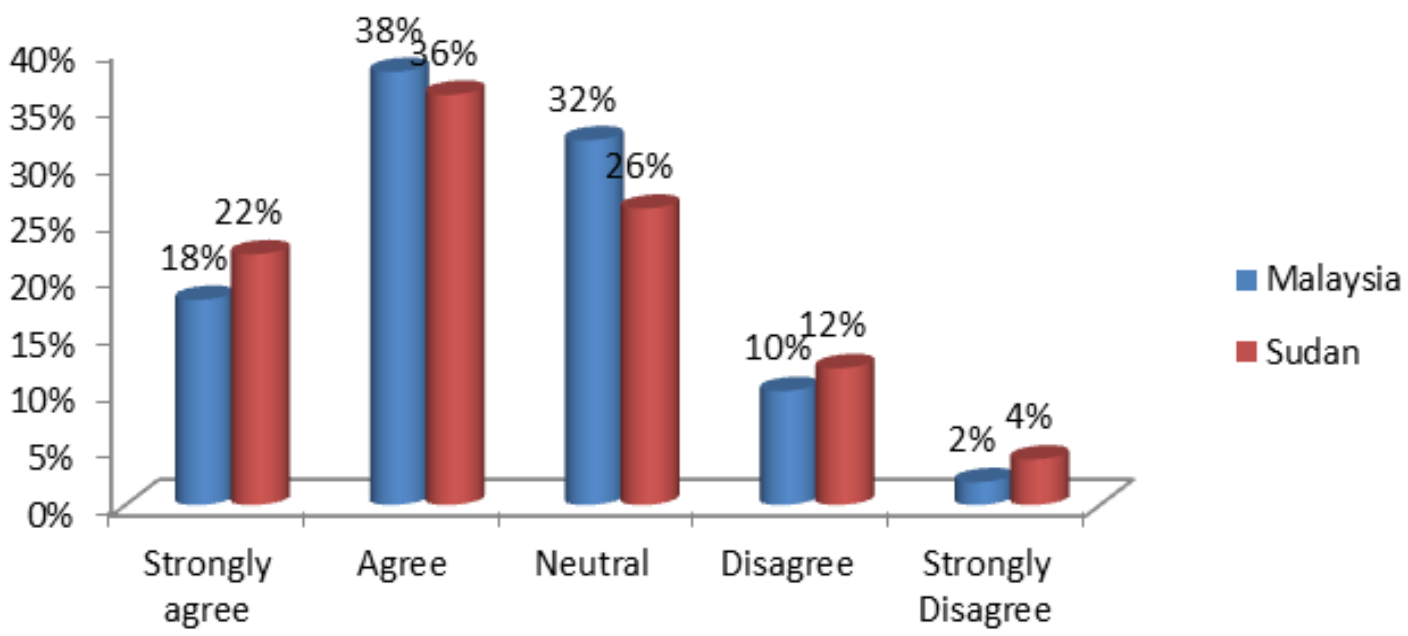

Fig. 5. Users' satisfaction with the time they took to perform a specified task.

The Table 5 and Fig. 5., show responses of participants to the statement related "their satisfaction with the time they take to perform a specified task"; results showed that in Malaysia (38\%) of participants agree and $(18 \%)$ strongly agree that they are satisfied with the time they take to perform a specified task while (32\%) were neutral, $(10 \%)$ of participants disagree and only $(2 \%)$ strongly disagree with the statement. results of the Sudanese participants were almost close to those results of Malaysia where (36\%) of participants agree and (22\%) strongly agree that they are satisfied with the time they take to perform a specified task while (26\%) were neutral, (12\%) of participants disagree and only (4\%) strongly disagree with the statement.

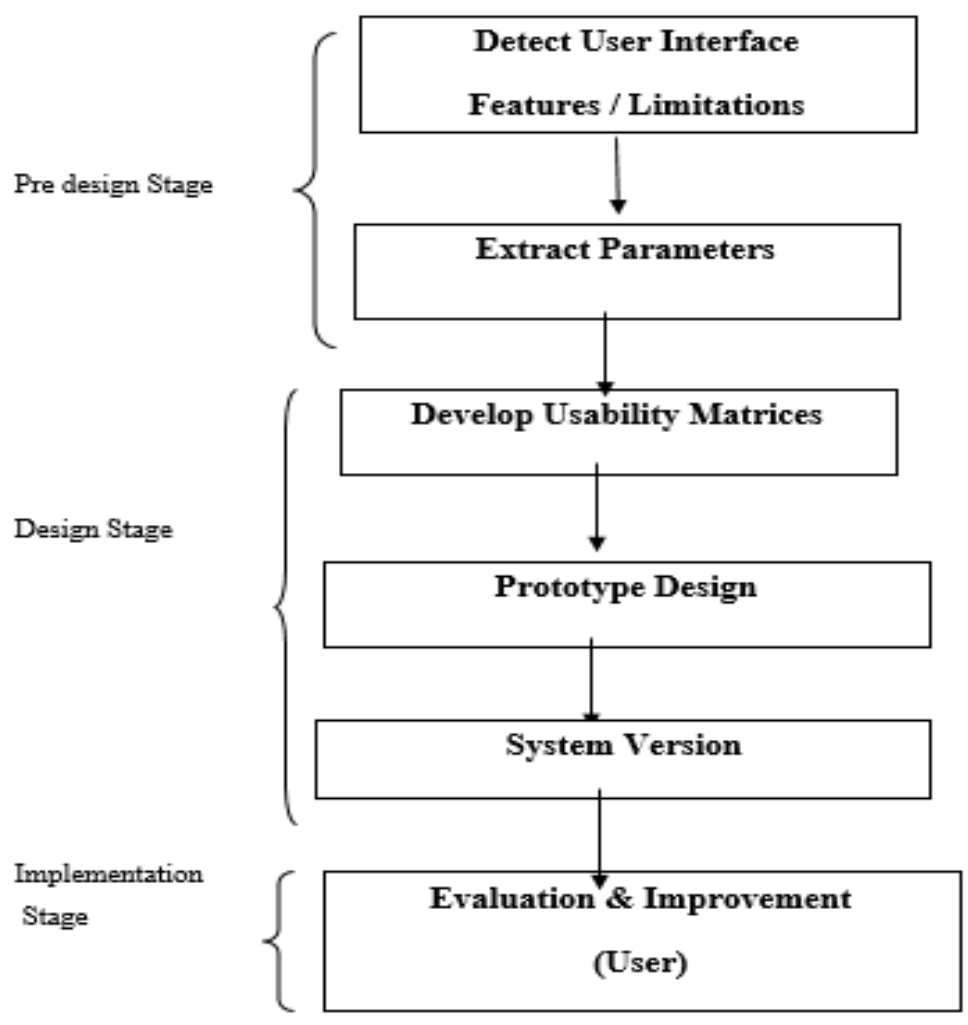

Fig. 6. The experiment framework. 


\section{Discussion}

The results revealed that (50\%) of participants frequently use the delete key, (44\%) frequently use the escape key. Concerning the ease of completing a specified task using the available computer application; results showed that (34\%) reported that they find it easy to complete specified tasks. The second part of the investigation was about completing the task without errors, $44 \%$ satisfied with percentage of errors they make in completing tasks. Also found (56\%) are satisfied with the time they take to perform a specified task In comparison of the Sudanese participants satisfaction ,results showed that $30 \%$ are satisfied with their accuracy in finishing tasks, $36 \%$ are satisfied with percentage of errors they make in completing tasks $58 \%$ are satisfied with the time they take to perform a specified task. These facts support the researcher decision for selecting the "time duration, accuracy, number of errors, number of using delete key and number of using escape key" as usability measurement parameters. In the following section, the experiment framework that will be used for auto generating of usability metrics has been presented.

\section{The Experiment Framework}

The proposed framework is organized into three stages. The first one is "Predesign Stage", it is divided into two sub stages. Starting with detecting the user interface like features and limitations. Secondly is extracting the parameters from monitoring user interface so that to help in designing better user interface applications. The second stage is called "Design Stage". The first procedure in it is developing usability matrices, next is designing the prototype and finally designing final system version after testing. The final stage is "Implementation Stage", which prioritize in evaluation and improvements.

\section{References}

[1] Fenton, M., \& Bieman, J. (2014). Software Metrics: A Rigorous and Practical Approach. Third Edition. Taylor and Francis group.

[2] Bosher, N. F. (2006). The spines of the channel catfish. Ictalurus punctatus, as an anti-predator adaptation: An experimental study.

[3] Hyun, A. A., Jafri, R., \& Benabid, A. (2017). Requirements' elicitation for a tangible interface-based educational application for visually impaired children.

[4] Emily, L. H., Ramkesh, R., Bryan, N. T., Alexa, J. C., Andrea, V. B., Amelia, B., Mathew, C. J., Anish, K., Ryan, S. K., Felix, A. L., Meilin, K. L., Laura, W. M., Amy, Z., Oliver, K. Z., \& Marcio, A. O. (2017). A review of principles in design and usability testing of tactile technology for individuals with visual impairments. Assistive Technology.

[5] Aljarallah, K., \& AlShathry, O. (2015). Blindness and online interaction: Beyond design standards. Computer Engineering and Intelligent Systems, 6(12).

[6] Mostafa, A. F. (2015). Moblogging type and its relation with usability and development knowledge management skills for blind students. International Journal of Education and Psychological Research (IJEPR). 4(3).

[7] Al-Glaly, Q., \& Smith-Jackson, D. (2013). Touch-screens are not tangible: Fusing tangible interaction with touch glass in readers for the blind. Proceedings of the 2013 - International Conference on Tangible, Embedded and Embodied Interaction.

[8] Sahasrabudhe, S., \& Lockley, M. (2014). Understanding blind user's accessibility and usability problems in the context of myITlab simulated environment. Proceedings of the 20th Americas Conference on Information Systems.

[9] Chalkia, E., Bekiaris, E., \& Madrid, L. I., (2016). How do needs and preferences of a user match the settings of the interfaces they use. Book Chapter in Advances in Ergonomics Modeling, Usability \& Special 


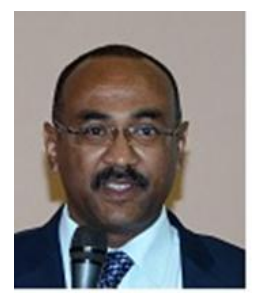

Mohamed Hashim was born in Sudan, in 1967. He received his B.Sc. (Honors) second class, division two - in computer science, School of Mathematical Sciences, University of Khartoum, Sudan. 1992; the M.Sc. in computer science, Faculty of Mathematical Sciences, University of Khartoum, Sudan. 2001; the PhD Candidate in information technology and communication- MSU - Malaysia.

His previous jobs were: deputy manager - touch \& technology Co. Ltd., administration and financial affairs executive officer - Bayan College for Science and Technology and lecturer- Future University. The current jobs are: general manager - Nilesoft Technology Co. Ltd., lecturer in Bayan College for Science \& Technology, and country manager - International Computer Driving Licenses Program (ICDL), Khartoum - Sudan. He published the following papers: Usability Measurement for Visually Impaired Users: A Study map Malaysia. MSU Journal. JMS2/0200. (2013, Feb). Usability Measurement for Visually Impaired Users: A Study map. Malaysia. MSU Journal JMS2/0200. (2013, Feb). Towards Developing Usability Measurements for Visually Impaired People's Software: a Road Map, 8th Int. Conference on Intelligent Information Processing, http://www.aicit.org/iciip. Korea. (2013, Apr.). A Study on Usability Measurements for Visually Impaired People's Software. Communications of the Arab Computer Society. Vol.7, No.1, ISSN:2090-102X, USA. (2014, Aug.). 